\title{
Attitudes toward uncertainty among the poor: an experiment in rural Ethiopia
}

\author{
Alpaslan Akay • Peter Martinsson • \\ Haileselassie Medhin • Stefan T. Trautmann
}

Published online: 30 March 2011

(C) The Author(s) 2011. This article is published with open access at Springerlink.com

\begin{abstract}
We investigate risk and ambiguity attitudes among Ethiopian farmers in one of the poorest regions of the world. Strong risk aversion and ambiguity aversion were found with the Ethiopian farmers. We compared their attitudes to those of a Western university student sample elicited by the same decision task. Ambiguity aversion was similar for farmers and students, but farmers were more risk averse. Our results show that ambiguity aversion is not restricted to Western student populations, and that studies of agricultural decisions may benefit from explicitly considering ambiguity attitudes.
\end{abstract}

Keywords Risk attitudes · Ambiguity attitudes $\cdot$ Poverty $\cdot$ Agriculture

JEL Classification $\quad \mathrm{D} 81 \cdot \mathrm{C} 93 \cdot \mathrm{O} 12$

\section{Introduction}

In June 2008 USAID transported 5000 layer and broiler chicks to Helmand province in Afghanistan to build the foundation for a privately owned poultry industry. The goal

\footnotetext{
A. Akay

IZA (Institute for the Study of Labor), Box 7240, 53072 Bonn, Germany

e-mail: akay@iza.org

P. Martinsson · H. Medhin

Department of Economics, University of Gothenburg, Box 640, 40530 Göteborg, Sweden

e-mail: peter.martinsson@economics.gu.se

H. Medhin

e-mail: haileselassie.medhin@economics.gu.se

S. T. Trautmann $(\bowtie)$

Department of Economics, TIBER \& CentER, Tilburg University, Tilburg, The Netherlands e-mail: s.t.trautmann@uvt.nl
} 
of the development program was to provide new income opportunities, and especially to provide a licit alternative to the production of opium poppy. For farmers, the payoffs from the current activity of growing poppy and from the potential alternative of poultry farming are both uncertain. Because of their experience with poppy production, and their inexperience with poultry, it is conceivable that Afghan farmers feel more competent in assessing the uncertainty involved in poppy than those in poultry farming.

In decision under uncertainty, research has shown that people distinguish between prospects for which they have a clear probability assessment or feel competent because of their own expertise, and prospects for which probabilities are unknown and they feel less competent (Abdellaoui et al. 2010; Heath and Tversky 1991). The extreme case of objectively known probabilities (e.g., of tails coming up in a coin flip) is called risk, and the extreme case of completely unknown probabilities (e.g., likelihood of rain tomorrow) is called ambiguity. Ellsberg (1961) suggested that people often prefer to bet on risky prospects instead of ambiguous prospects, even if expected utility theory implies indifference. Confirming Ellsberg's conjecture, ambiguity aversion has been found in many empirical studies, including under market conditions and with monetary incentives (Cabantous 2007; Halevy 2007; Muthukrishnan et al. 2009; Sarin and Weber 1993).

A significant number of decisions under uncertainty is made by farmers and fishermen in developing regions of the world who often live near or below the poverty line, and for whom uncertainty affects their existence. Uncertainty in such settings has usually been studied assuming well defined probabilities of the possible outcomes. In many decisions, however, it is more likely that ambiguity as defined above prevails, with little information about actual probabilities available. Typical examples include the uptake and adaptation of new crops, new production technologies (e.g., fertilizer) and investments that involve unknown risks (e.g., water harvesting). While uncertainty has been identified as an important determinant of such farm technology adoption and subsequent effects on economic growth (Feder 1980; Feder et al. 1985; Kebede 1992), the literature does not differentiate between the effect of risk aversion and ambiguity aversion.

The aim of this article is to experimentally test whether ambiguity aversion is prevalent among small scale farmers. In particular, the current study reconsiders the findings of the only study so far on ambiguity attitudes in farming societies (Henrich and McElreath 2002). Henrich and McElreath studied risk and ambiguity attitude among Chilean Mapuche small scale farmers and found no evidence for ambiguity aversion. They argued that ambiguity aversion may be driven by cultural factors, and that it does not generalize to non-Western farming societies. More generally, Henrich and McElreath's study makes the important point that uncertainty attitudes may not always generalize from typical undergraduate student populations toward culturally and demographically different groups that are of economic interest. ${ }^{1}$ However, their interpretations may not be completely convincing either. Two points of concern with their results are that their experiment had little power to identify ambiguity aversion,

\footnotetext{
${ }^{1}$ Giordani et al. (2010) also demonstrate this fact in a study mapping cross-cultural differences in uncertainty attitude across countries in the European Union.
} 
and that there was no control experiment using a typical participant pool to put the findings into the perspective of the larger literature. ${ }^{2}$ As we will show below, differences in the decision tasks compared to previous studies with student samples at Western universities can provide an obvious explanation for the observed ambiguity attitudes in the absence of a control group.

This article measures risk and ambiguity attitudes among small scale farmers in rural Ethiopia using an experiment with real monetary incentives, and compares the results to data from university students in the Netherlands facing the same decision tasks. Our Ethiopian participants differ from typical undergraduate subject pools in terms of their occupation, wealth, and cultural background. We find clear evidence for ambiguity aversion with both the Ethiopian farmers and the Dutch students. The result shows that studies of farming decisions may benefit from the inclusion of ambiguity. Farmers are more risk averse than the students. For the farmers we relate their risk and ambiguity attitudes to socio-economic variables and health status. Poor health is positively related to risk and ambiguity aversion. The next section gives a description of the participant pool and introduces the experimental design. The results are presented in Sect. 3 and discussed in Sect. 4.

\section{Participants and experimental design}

\subsection{Participants}

The experiment was conducted in the village of Abraha We Atsbaha in the northern highlands of Ethiopia. The majority of the Ethiopian population resides in the highlands, where small-scale subsistence agriculture is the main economic activity. Highland agriculture in Ethiopia is characterized by population pressure, extreme land fragmentation, severe soil degradation, and heavy dependence on rainfall. As a result, the overall outcome is one of the lowest agricultural productivity levels in the world. During the last few decades, the number of droughts has exacerbated the problem, especially in the northern parts of the country. Abaraha We Atsbaha is one of many poor villages in a region where most people depend on food aid programs to survive between the two annual harvests.

Our sample consisted of 92 adults with little or no formal education, and $30 \%$ of those who participated in our experiment were illiterate. Subjects were randomly selected from a list of 584 households, with either the male or female household head participating. All subjects were small scale farmers and mainly growing wheat, maize, barley, and teff. Most families also own some livestock such as cattle and sheep. All participants were Christians.

\footnotetext{
2 In particular, Henrich and McElreath rejected ambiguity aversion because they found that a majority of farmers preferred an ambiguous prospect paying either 5000 pesos or zero, over a sure payoff of 1000 pesos. Note that for a risk and ambiguity neutral subject this payoff calibration implies a preference for the sure payoff over the ambiguous prospect only for expected probabilities smaller than $20 \%$. Thus, even a significantly risk and ambiguity averse agent may prefer the prospect over the sure payment.
} 


\subsection{Payoffs}

Each participant could win up to 20 Ethiopian birr (ETB). At the time of the experiment the exchange rate was ETB $9.67=$ US\$ 1. In this region, the daily wage for unskilled farm labor varies between 10-15 Birr, depending on the season. Thus, the stakes involved roughly corresponds to 2 daily wages.

\subsection{Procedure}

We elicited each participant's certainty equivalents for a risky and an ambiguous prospect: the sure payment such that the subject is indifferent between receiving the prospect or the sure amount. The risky prospect allowed the participant to bet on the color of a ball drawn from a bag with exactly 5 white and 5 yellow balls, and to win ETB 20 if they correctly guessed the color. This prospect thus offers a 50-percent chance to win the prize. The ambiguous prospect allowed participants to bet on the color of a ball drawn from a bag with 10 balls, where the proportion of white and yellow balls was unknown. If subjects guessed the color correctly, they won ETB 20.

These two prospects represent the risky and ambiguous option in the Ellsberg (1961) two-color choice task. The ambiguous option is always at least as good as the risky option. If participants are indifferent between betting on either color in the ambiguous option, they should be indifferent between playing the bet with the risky option or with the ambiguous option. In this case, they will have identical certainty equivalents for both options. If they believe that there are more white balls than yellow balls in the ambiguous bag, they will bet on white in the ambiguous prospect and should prefer this prospect over the risky prospect. A similar argument holds if the participants believe that there are more yellow balls in the ambiguous bag. A preference for the risky prospect thus reveals ambiguity aversion.

For each prospect, we elicit participants' certainty equivalents using a choice list. Subjects made 20 choices between a sure payoff and playing the prospect, and these choices were arranged in an ordered list. The sure payoff increases from ETB 1 to ETB 20 when going down the list. For very small sure payoffs, most participants will prefer to play the prospect; for very large sure payoffs, most participants will prefer the sure cash. That is, most participants will switch from sure cash to playing the prospect at some point. We calculate the certainty equivalent as the midpoint between the lowest sure payoff for which the participant takes the sure cash and the highest sure payoff for which the participant prefers to play the prospect. ${ }^{3}$

Choice lists are popular in experimental economics studies (e.g., Holt and Laury 2002). Our lists involve the simplest possible structure, with each choice involving the same risky (ambiguous) prospect and some sure amount. Note that this choice list methodology differs from the list employed by Binswanger (1980), where participants were asked to choose one prospect from a list of prospects that differed with respect to

\footnotetext{
3 Illustrations and instructions are provided in the online appendix: http://dl.dropbox.com/u/11242744/ Akayetal2011_Online\%20Appendix.pdf
} 
their expected payoff and variance, and the selected prospect then served as an index of risk aversion. Our method directly elicits the certainty equivalent of each prospect.

Participants made choices in one choice list for each prospect, and therefore, they made 40 choices in total. After the participants made all choices, one of these choices was randomly selected for real play for each participant. Depending on the decision in the selected choice problem, the participant received either the sure cash amount or played the prospect with a chance to win ETB 20.

Because most of our subjects had no formal education and many were illiterate, the instructions were given verbally in local language, using posters as visual aids. All probabilities and randomizations were demonstrated using balls and dice, and no explicit reference to probabilities was given. Visual aids have been shown to improve the understanding of risks by participants without formal training in probability theory and were clearly necessary in our sample (Carlsson et al. 2004; Corso et al. 2001). The prospects and the betting tasks were demonstrated for the risky option by filling the bag with 5 white and 5 yellow balls. A subject chose a color by putting a ball of this color on the table. Next, a ball was randomly drawn by the participants from the bag. If the colors matched, the subject was paid ETB 20. The actual experiment was conducted with one participant at a time in a private area. The binary choices between the prospects and the sure amounts of money were presented to the participant one choice at a time. The experimenter filled out the choice list according to the participant's preference in each choice until all 40 choices had been filled out.

\subsection{Control group}

As a comparison standard, we use data from an experiment with undergraduate university students at a Dutch university facing the same decision task as above (Trautmann et al. 2011, experiment 4). The tasks and randomizations were done in the same (noncomputerized) way as for the farmers. The prize was $€ 50$ for the two prospects for the student sample, and 2 of 79 students were randomly selected for real play of their choices. Students received written instructions and filled out the choice lists themselves. The student experiments were conducted in a classroom.

\section{Experimental results}

\subsection{Risk and ambiguity attitudes}

\section{Risk attitudes}

The certainty equivalents for the risky prospect allow us to control for risk attitude in the measurement of ambiguity below. Risk attitudes are of independent interest, however, and we report the data here. In this section, we assume expected utility with power utility and report constant relative risk aversion (CRRA) coefficients. This is the most common specification in the literature and we can thus benchmark our results to previous findings. With the simple two-outcome gain prospects studied here, 
Table 1 Distribution of constant relative risk aversion parameters in Ethiopian farmers versus university student samples

\begin{tabular}{|c|c|c|c|c|}
\hline & $\begin{array}{l}\text { Risk } \\
\text { neutral/ } \\
\text { loving }\end{array}$ & $\begin{array}{l}\text { Mildly risk } \\
\text { averse }\end{array}$ & $\begin{array}{l}\text { Risk } \\
\text { averse }\end{array}$ & $\begin{array}{l}\text { Highly } \\
\text { risk averse }\end{array}$ \\
\hline & $\rho \leq 0.15(\%)$ & $0.15<\rho \leq 0.41(\%)$ & $0.41<\rho \leq 0.68(\%)$ & $\rho>0.68(\%)$ \\
\hline Ethiopian farmers $(n=92)$ & 22 & 11 & 10 & 58 \\
\hline Dutch students $(n=79)^{\mathrm{a}}$ & 19 & 35 & 44 & 1 \\
\hline U.S. students $(n=93)^{\mathrm{b}}$ & 19 & 19 & 23 & 39 \\
\hline
\end{tabular}

a Trautmann et al. (2011)

b Holt and Laury (2002, p. 1649, Table 3, last column). Identical tasks in Ethiopia and the Netherlands. A slightly different task has been used for U.S. student by Holt and Laury, with all choice options involving only non-degenerated gambles

the results do not change if we assume linear utility and interpret risk aversion in terms of probability weighting as in rank dependent utility and prospect theory. ${ }^{4}$

The median coefficient of relative risk aversion in the Ethiopian sample is $\rho=0.73$, which is significantly larger than the median of $\rho=0.34$ in the Dutch student sample (Mann-Whitney $U$ test, $z=4.391, P<0.01$ ). Table 1 shows that the percentage of risk-neutral and seeking participants is similar in both groups, but that among the farmers there are few mildly and medium risk averse. In particular, 41 of the 92 participants in Ethiopia preferred the sure payoff in all choices. The table also includes the distribution of CRRA parameters estimated by Holt and Laury (2002) for a sample of U.S. students using real payoffs up to $\$ 77$ (see Holt and Laury 2002, p. 1649, Table 3, last column). This study is often used as a benchmark in the economics literature. Their study indicates more risk aversion than did the Dutch study and the distribution was closer to our Ethiopian sample. However, Holt and Laury (2002) had only about $40 \%$ highly risk-averse participants, compared to the $60 \%$ highly risk averse in our experiment. Thus, the main difference between the farmers and the students is the presence of a significant minority in the former group that strictly avoids uncertainty. ${ }^{5}$

\section{Ambiguity attitudes}

Ambiguity attitude refers to the difference between the evaluation of the risky prospect and the ambiguous prospect. As a measure of ambiguity aversion, we employ the value

\footnotetext{
${ }^{4}$ Because we have only one indifference point (one certainty equivalent for one risky prospect), we would have to restrict the analysis to single-parameter probability weighting functions. Estimation of more flexible weighting functions requires more information and therefore more complex elicitation procedures (Abdellaoui 2000; Bleichrodt and Pinto 2000; Booij et al. 2010). See Botzen and Van den Bergh (2009) and Humphrey and Verschoor (2004) for such measurements in an environmental/agricultural context.

5 Interestingly, Cohen et al. (2010) report a similar finding of extreme risk aversion for a French non-student population sample.
} 
certainty equivalent risky prospect - certainty equivalent ambiguous prospect

certainty equivalent risky prospect + certainty equivalent ambiguous prospect .

That is, ambiguity aversion is defined as the difference between the subject's certainty equivalent of the risky prospect and her certainty equivalent of the ambiguous prospect, normalized by the sum of the two certainty equivalents. This measure ranges from -1 (ambiguity loving) to 0 (ambiguity neutrality) to 1 (ambiguity averse). The larger the difference between the two certainty equivalents is, the stronger the ambiguity attitude. The normalization controls for the fact that a difference of ETB 2 weighs more heavily for a subject who is very risk averse (e.g., certainty equivalent risky prospect of ETB 4) than for a subject who is relatively risk neutral (e.g., certainty equivalent risky prospect of ETB 9).

Because of the strong risk aversion in the Ethiopian sample, we have 41 participants who revealed the lowest feasible certainty equivalent for the risky prospect. For these participants we cannot distinguish between ambiguity neutrality and aversion, and therefore, we excluded them from the analysis. Table 4 in the Appendix shows that the ambiguity attitudes of the excluded subject were very similar to those of the included subjects. Ambiguity attitudes did not differ between the Ethiopian farmers and the Dutch students (Mann-Whitney $U$ tests, $z=1.535, P$ value $>0.1$ ). In both samples, we found clear ambiguity aversion (Wilcoxon tests, $P$ values $<0.01$ ). Table 2 shows the distribution of ambiguity attitudes in the Ethiopian and the Dutch samples, based on certainty equivalents, and in three comparison studies. Roca et al. (2006) gave British university students a direct choice between betting on the color in the risky or the ambiguous Ellsberg two-color urn. The distribution of ambiguity aversion in their basic experiment replicates standard findings in the literature and is similar to our results in Ethiopia.

The two other studies illustrate the effect of two design features on ambiguity attitude. The differences caused by these design variations are much stronger than the differences between the different samples of participants in the first three rows of the table. Chesson and Viscusi (2003) studied ambiguity attitude for loss prospects among business owners in the U.S. Clearly, there is more ambiguity seeking in their study compared to the current study, consistent with findings for losses in the literature (Cohen et al. 1985; Hogarth and Kunreuther 1985; Kahn and Sarin 1988). Keren and Gerritsen (1999) elicited Dutch university students' willingness-to-pay (WTP) for the risky and the ambiguous Ellsberg two-color urn. They found clear ambiguity aversion, and almost none of the subjects were willing to pay more for the ambiguous option. It is clear from the table that studies of non-student and non-Western subject pools should either apply established procedures, or include an explicit student control group before claims about the generalizability of preferences (or the lack thereof) can convincingly be made.

\subsection{Effects of demographic variables}

Before the experiment was conducted, the Ethiopian participants were interviewed on a number of socio-economic background variables. In the econometric analysis, 
Table 2 Ambiguity attitudes among Ethiopian peasants versus comparison samples

\begin{tabular}{|c|c|c|c|c|}
\hline & $\begin{array}{l}\text { Ambiguity } \\
\text { seeking }(\%)\end{array}$ & $\begin{array}{l}\text { Ambiguity } \\
\text { neutral (\%) }\end{array}$ & $\begin{array}{l}\text { Ambiguity } \\
\text { averse }(\%)\end{array}$ & $\begin{array}{l}\text { Elicitation } \\
\text { Method }\end{array}$ \\
\hline $\begin{array}{l}\text { Ethiopian farmers } \\
\quad(n=51)\end{array}$ & 20 & 24 & 57 & $\mathrm{CE}$, gains, real incentives \\
\hline $\begin{array}{l}\text { Dutch students } \\
(n=79), \\
\text { Trautmann et al. } \\
(2011)\end{array}$ & 15 & 43 & 42 & $\mathrm{CE}$, gains, real incentives \\
\hline $\begin{array}{l}\text { British students } \\
\quad(n=72), \text { Roca et al. } \\
(2006)\end{array}$ & 39 & n.a. & 61 & Choice, gains, hypothetical \\
\hline $\begin{array}{l}\text { Business owners } \\
\quad(n=130), \text { Chesson } \\
\text { and Viscusi (2003) }\end{array}$ & 56 & n.a. & 44 & Choice, losses, hypothetical \\
\hline $\begin{array}{l}\text { Dutch students } \\
\quad(n=39), \text { Keren and } \\
\text { Gerritsen (1999) }\end{array}$ & 3 & 46 & 51 & WTP, gains, hypothetical \\
\hline
\end{tabular}

Notes: Identical tasks in Ethiopia and the Netherlands. Roca et al. (2006), Table 1, control; Chesson and Viscusi (2003), Table III, panel B; Keren and Gerritsen (1999), Table 4, panel b

we regress the risk and ambiguity attitudes on this set of explanatory variables. The background variables include personal information and family background, but also measures of economic well-being. Wealth is approximated by land size, while income is measured by consumption. Consumption is used because it fluctuates much less than direct measures of income which vary a lot due to harvesting periods.

For risk attitude we avoid dependence on expected utility assumptions by using the pure certainty equivalent multiplied by -1 as an index or risk aversion. ${ }^{6}$ In the regressions, we control for censoring of our measure because a sizable fraction of participants revealed the lowest possible certainty equivalent. Thus, we used a Tobit model for our analysis of risk attitude. We also tested whether socio-economic variables explain the presence of extreme risk attitudes by including a Probit regression for dummy variable that assumes the value of 1 if the certainty equivalent is censored at 1 , and 0 otherwise. For ambiguity attitude, we apply OLS regressions for the measure described above because there is no censoring of ambiguity attitude. Regression results are shown in Table 3. Positive parameter values in the regressions imply increasing risk or ambiguity aversion, or increasing likelihood to show extreme level of risk aversion, respectively. Marginal effects are reported for the probit regression.

The regression results show that poor health is related both to stronger risk aversion and stronger ambiguity aversion. In particular, for risk, the subjects with poor health status demonstrate extreme risk aversion. Apart from health effects, we find that household size increases risk aversion, while being married is correlated with reduced ambiguity aversion. No other socio-economic variables had an influence on uncertainty attitudes in our data.

\footnotetext{
6 The higher the certainty equivalent, the lower the risk aversion.
} 
Table 3 Regression analysis for risk and ambiguity aversion for the Ethiopian sample

\begin{tabular}{llll}
\hline Explanatory variable & \multicolumn{2}{l}{ Dependent variable } & \\
\cline { 2 - 4 } & $\begin{array}{l}\text { Risk aversion } \\
\text { (Tobit) }\end{array}$ & $\begin{array}{l}\text { Extreme risk } \\
\text { aversion (Probit) }\end{array}$ & $\begin{array}{l}\text { Ambiguity } \\
\text { aversion (OLS) }\end{array}$ \\
\hline Age & $-0.562(.573)$ & $-0.046(0.031)$ & $-0.030(0.026)$ \\
Age $^{2} / 100$ & $0.419(0.574)$ & $0.041(0.031)$ & $0.029(0.023)$ \\
Female & $-2.941(2.557)$ & $-0.089(0.142)$ & $-0.129(0.146)$ \\
Poor Health & $5.265 *(2.822)$ & $0.344 *(0.133)$ & $0.339 *(0.154)$ \\
Married & $-3.887(3.430)$ & $-0.174(0.183)$ & $-0.433 * *(0.167)$ \\
Household size & $1.574 *(0.836)$ & $0.102 * *(0.044)$ & $0.045(0.062)$ \\
Number of dependent children & $-0.886(1.006)$ & $-0.029(0.053)$ & $0.029(0.045)$ \\
Land size & $-0.192(1.203)$ & $-0.007(0.069)$ & $0.092(0.073)$ \\
Consumption (100 ETB) & $0.016(0.245)$ & $0.006(0.013)$ & $0.014(0.010)$ \\
Number of observations & 84 & 84 & 45 \\
\hline Notes. & & & \\
\hline
\end{tabular}

Notes. $* *$, * denote significance at the 5 and $10 \%$ level, standard errors in parenthesis (robust standard errors for OLS). Marginal effects are reported for the Probit regression

\section{Discussion and conclusions}

There has been much interest in cross country differences in attitudes towards uncertainty, and numerous studies have measured attitudes toward prospects with objectively known payoff distributions in developing countries and small scale societies (Binswanger 1980; Bohnet et al. 2008; Kuznar 2001; Yesuf and Bluffstone 2009; Harrison et al. 2010; Dillon and Scandizzo 1978; Elamin and Rogers 1992). Most of these studies found a similar degree of risk aversion as in typical student samples from developed countries. Henrich and McElreath (2002) showed that there can be significant differences between culturally diverse farming societies, however. These authors also suggested the importance of cross cultural comparison of attitudes toward ambiguous prospects, when probabilities are unknown. In the real world ambiguity is ubiquitous; ambiguity-driven preferences between traditional technologies with wellknown payoff distributions and new technologies and crops with unknown risks would therefore be relevant to innovation and development. Henrich and McElreath report, however, that ambiguity aversion is not prevalent in their farmers. They suggest that ambiguity aversion may be restricted to Western student populations.

We measure ambiguity aversion in a sample of Ethiopian small scale farmers, using real incentives and concrete visual representations of prospects in terms of differently colored balls in urns. We compared the Ethiopian data to data from an experiment among Western university students using exactly the same decision task. We have shown that holding design features constant between groups is necessary to draw conclusions regarding cross cultural differences (see also Bohnet et al. 2008; Kocher et al. 2008; Roth et al. 1991).

We find both risk aversion and ambiguity aversion for Ethiopian farmers. Risk aversion was stronger for the farmers than for the comparison student samples, 
and this effect is driven by extreme risk attitudes for a significant minority of the farmers. Comparing the distribution of risk attitudes with other findings from Western student populations shows, however, that variation is well within the range of the variation expected across different experiments. In any case, the data support the view that strong risk aversion predominates among the farmers. Ambiguity aversion did not differ between Ethiopian peasants and Dutch university students, and both groups show ambiguity aversion. Ambiguity attitudes in the samples considered in our study are also comparable to other findings reported in the literature.

Attitudes toward uncertainty are important factors in the analysis of economic problems and policy in developing countries. Risk-sharing, crop selection, and precautionary saving influence welfare in risky agricultural environments and are influenced by economic actors' attitudes toward risk (Dercon 1996; Jalan and Ravallion 2001; Kochar 1999; Pan 2009; Udry 1994). On the other hand, ambiguity aversion has been widely observed among student samples, and has been proposed as an explanation for various market phenomena (e.g., Mukerji and Tallon 2001; Peijnenburg 2011; Zeckhauser 2006). We find that Ethiopian small scale farmers exhibit ambiguity aversion. Our result shows that empirical studies on farming decisions in developmental context may benefit from the inclusion of ambiguity attitudes.

Acknowledgments Financial support from the Swedish Research Council (Vetenskapsrådet), the Jan Wallander and Tom Hedelius Foundation, and Sida (Swedish International Development Cooperation Agency) to the Environmental Economics Unit at the University of Gothenburg is gratefully acknowledged. Trautmann acknowledges financial support by a VENI grant of the Netherlands Foundation for Scientific Research (NWO).

Open Access This article is distributed under the terms of the Creative Commons Attribution Noncommercial License which permits any noncommercial use, distribution, and reproduction in any medium, provided the original author(s) and source are credited.

\section{Appendix: ambiguity attitudes of excluded subjects}

Table 4 Ambiguity attitudes in the included sample and the excluded sample

\begin{tabular}{llll}
\hline & All & Included $(\mathrm{CE}$ risk $>1)$ & Excluded $(\mathrm{CE}$ risk $=1)$ \\
\hline Ambiguity seeking & $18(19 \%)$ & $10(20 \%)$ & $8(19 \%)$ \\
Ambiguity neutral & $46(50 \%)$ & $12(24 \%)$ & $34(81 \%)$ \\
Ambiguity averse & $29(31 \%)$ & $29(56 \%)$ & \\
\hline
\end{tabular}

\section{References}

Abdellaoui, M. (2000). Parameter-free elicitation of utility and probability weighting functions. Management Science, 46, 1497-1512.

Abdellaoui, M., Baillon, A., Placido, L., \& Wakker, P. P. (2010). The rich domain of uncertainty. American Economic Review, forthcoming.

Binswanger, H. P. (1980). Attitudes toward risk: Experimental measurement in rural India. American Journal of Agricultural Economics, 62, 395-407. 
Bleichrodt, H., \& Pinto, J. L. (2000). A parameter-free elicitation of the probability weighting function in medical decision analysis. Management Science, 46, 1485-1496.

Bohnet, I., Greig, F., Hermann, B., \& Zeckhauser, R. (2008). Evidence from Brazil, China, Oman, Switzerland, Turkey, and the United States. American Economic Review, 98, 294-310.

Booij, A. S., Van Praag, B. M. S., \& Vande Kuilen, G. (2010). A parametric analysis of prospect theory's functionals for the general population. Theory and Decision, 68, 115-148.

Botzen, W. J. W., \& Vanden Bergh, J. C. J. M. (2009). Bounded rationality, climate risk, and insurance: Is there a market for natural disasters. Land Economics, 85, 265-278.

Cabantous, L. (2007). Ambiguity aversion in the field of insurance: Insurers' attitude to imprecise and conflicting probability estimates. Theory and Decision, 62, 219-240.

Carlsson, F., Johansson-Stenman, O., \& Martinsson, P. (2004). Is transport safety more valuable in the air? Journal of Risk and Uncertainty, 28, 147-163.

Chesson, H. W., \& Viscusi, W. K. (2003). Commonalities in time and ambiguity aversion for long-term risks. Theory and Decision, 54, 57-71.

Cohen, M., Jaffray, J. Y., \& Said, T. (1985). Individual behavior under risk and uncertainty: An experimental study. Theory and Decision, 18, 203-328.

Cohen, M., Tallon, J.-M., \& Vergnaud, J.-C. (2010) An experimental investigation of imprecision attitude and its relation with risk attitude and impatience. Theory and Decision, forthcoming.

Corso, P., Hammitt, J. K., \& Graham, J. D. (2001). Valuing mortality-risk reduction: Using visual aids to improve the validity of contingent valuation. Journal of Risk and Uncertainty, 23, 165-184.

Dercon, S. (1996). Risk, crop choice, and savings: Evidence from Tanzania. Economic Development and Cultural Change, 44, 485-513.

Dillon, J. L., \& Scandizzo, P. L. (1978). Risk attitudes of subsistence farmers in Northeast Brazil: A sampling approach. American Journal of Agricultural Economics, 60, 425-435.

Elamin, E. M., \& Rogers, L. F. (1992). Estimation and use of risk aversion coefficients for traditional dryland agriculture in western Sudan. Agricultural Economics, 7, 155-166.

Ellsberg, D. (1961). Risk, ambiguity and the Savage axioms. Quarterly Journal of Economics, 75, 643-669.

Feder, G. (1980). Farm size, risk aversion and the adoption of new technology under uncertainty. Oxford Economic Papers, 32, 263-283.

Feder, G., Just, R., \& Zilberman, D. (1985). Adoption of agricultural innovations in developing countries: A survey. Economic Development and Cultural Change, 33, 255-298.

Giordani, P. E., Schlag, K. H., \& Zwart, S. (2010). Decision makers facing uncertainty: Theory versus evidence. Journal of Economic Psychology, 31, 659-675.

Halevy, Y. (2007). Ellsberg Revisited: An experimental study. Econometrica, 75, 503-536.

Harrison, G. W., Humphrey, S. J., \& Verschoor, A. (2010). Choice under uncertainty: Evidence from Ethiopia, India and Uganda. Economic Journal, forthcoming.

Heath, C., \& Tversky, A. (1991). Preference and belief: Ambiguity and competence in choice and uncertainty. Journal of Risk and Uncertainty, 4, 5-28.

Henrich, J., \& McElreath, R. (2002). Are peasants risk-averse decision makers? Current Anthropology, 43, 172-181.

Hogarth, R. M., \& Kunreuther, H. (1985). Ambiguity and insurance decisions. American Economic Review, 75, 386-390.

Holt, C. A., \& Laury, S. K. (2002). Risk aversion and incentive effects. American Economic Review, 92, 1644-1655.

Humphrey, S. J., \& Verschoor, A. (2004). Decision-making under risk among small farmers in East Uganda. Journal of African Economies, 13, 44-101.

Jalan, J., \& Ravallion, M. (2001). Behavioral responses to risk in rural China. Journal of Development Economics, 66, 23-49.

Kahn, B. E., \& Sarin, R. K. (1988). Modeling ambiguity in decisions under uncertainty. Journal of Consumer Research, 15, 265-272.

Kebede, Y. (1992). Risk behaviour and agricultural technologies: The case of producers in central highlands of Ethiopia. Quarterly Journal of International Agriculture, 31, 269-284.

Keren, G. B., \& Gerritsen, L. E. M. (1999). On the robustness and possible accounts of ambiguity aversion. Acta Psychologica, 103, 149-172.

Kochar, A. (1999). Smoothing consumption by smoothing income: hours-of-work responses to idiosyncratic agricultural shocks in rural India. Review of Economics and Statistics, 81, 50-61. 
Kocher, M. G., Cherry, T., Kroll, S., Netzer, R. J., \& Sutter, M. (2008). Conditional cooperation on three continents. Economics Letters, 101, 175-178.

Kuznar, L. A. (2001). Risk sensitivity and value among Andean pastoralists: Measures, models, and empirical tests. Current Anthropology, 42, 432-440.

Mukerji, S., \& Tallon, J.-M. (2001). Ambiguity aversion and incompleteness of financial markets. Review of Economic Studies, 68, 883-904.

Muthukrishnan, A. V., Wathieu, L., \& Xu, A. J. (2009). Ambiguity aversion and persistent preference for established brands. Management Science, 55, 1933-1941.

Pan, L. (2009). Risk pooling through transfers in rural Ethiopia. Economic Development and Cultural Change, 57, 809-835.

Peijnenburg, K. (2011). Life-cycle asset allocation with ambiguity aversion and learning. CentER working paper.

Roca, M., Hogarth, R. M., \& Maule, A. J. (2006). Ambiguity seeking as a result of the status quo bias. Journal of Risk and Uncertainty, 32, 175-194.

Roth, A. E., Prasnikar, V., Okuno-Fujiwara, M., \& Zamir, S. (1991). Bargaining and market behavior in Jerusalem, Ljubljana, Pittsburgh, and Tokyo: An experimental study. American Economic Review, 81, 1068-1095.

Sarin, R. K., \& Weber, M. (1993). Effects of ambiguity in market experiments. Management Science, 39, 602-615.

Trautmann, S. T., Vieider, F. M., \& Wakker, P. P. (2011). Preference reversals for ambiguity aversion. Management Science, forthcoming.

Udry, C. (1994). Risk and insurance in a rural credit market: An empirical investigation in northern Nigeria. Review of Economic Studies, 61, 495-526.

Yesuf, M., \& Bluffstone, R. (2009). Poverty, risk aversion, and path dependence in low income countries: Experimental evidence from Ethiopia. American Journal of Agricultural Economics, 91, 1022-1037.

Zeckhauser, R. J. (2006). Investing in the unknown and unknowable. Capitalism and Society 1, Article 5. 